\title{
Training of Adult Trainers: Implementation and Evaluation of a Higher Education Program in Greece
}

Azarias A. Mavropoulos ${ }^{1}$, Aikaterini K. Sipitanou ${ }^{1}$, and Anastasia A. Pampouri ${ }^{2}$

${ }^{1}$ Aristotle University of Thessaloniki, 54124 Thessaloniki, Greece, ${ }^{2}$ School of Social Sciences, Humanities and Arts, University of Macedonia, 54636 Thessaloniki, Greece

\begin{abstract}
This article presents the implementation and the evaluation of the blended learning program Training of Lifelong Learning Adult Trainers, which was organized by the Center of Training and Lifelong Learning of the Aristotle University of Thessaloniki in Greece, during the last two years (2016-2017). The aim of the training program was to give the opportunity to adult trainers to certify their educational competence and update their knowledge in the field of adult education, enhancing their employability. After the completion of the program, the trainees assessed the implementation methodology, the educational content, the microteachings, the quality, and the organization of the program. The results of the evaluation showed that the program was of a high level, flawlessly organized, and with excellent educational material, while the blended learning model worked effectively, receiving positive reviews by the participants. It was concluded that blended learning is indeed adequate in adult educational programs increasing the participation and facilitating adult trainees to better integrate their learning experiences.
\end{abstract}

Keywords: blended learning, lifelong learning, training of adult trainers, higher education, employability 


\section{Introduction}

The increasing number of institutions and organizations that offer adult and continuing education programs in Greece has led to a rise in the human resources involved in the design, organization, and implementation of these programs. Therefore, it is necessary that these human resources be welltrained. A relevant study carried out in 2002 showed that although there were enough adult trainers in Greece who had experience and knowledge of their cognitive field, they were behind the use of modern active teaching techniques, the design of teaching modules and educational programs, and the manipulation of the dynamics of the relationships formed within the trainees' group (Kokkos, 2007).

By the year 2019, certified educational adequacy will be a prerequisite for a trainer in order to participate in a public funded non-formal educational program. Thus, a trainee candidate who does not have the required legal experience in adult education will be referred to a training program of adult trainers, implemented by a public sector body.

In order to meet this need for training, many bodies, institutions, and universities in Greece have begun to set up training for adult trainers programs, aiming both at upgrading their qualifications and preparing for the certification exams for the adult educational adequacy (Kokkos \& Karalis, 2011).

In this study we are examining the program Training of Lifelong Learning Adult Trainers organized by the Center of Training and Lifelong Learning (KEDIVIM) of the Aristotle University of Thessaloniki. Six cycles of studies have been implemented since October 2016 to December 2017 and each cycle lasted between seven to 11 weeks.

The Center of Training and Lifelong Learning (KEDIVIM) is a unit of the Aristotle University of Thessaloniki and develops interdisciplinary training, continuing education, and lifelong learning programs, which are offered either by face-to-face or by distance learning. The operation of such programs is now more urgent than ever, as they contribute to reducing social exclusion, upgrading the quality of education, and enhancing the employability of trainees. This program is directed to:

- prospective adult trainers of all cognitive subjects, who want to be trained, in order to certify their educational adequacy and teach their subject to adult learners;

- those registered in the National Organization for the Certification of Qualifications and Vocational Guidance as well as in other registers of adult trainers, who want to update their knowledge in the field of adult education; and

- existing and prospective staff members of lifelong learning structures, such as Institutes of Vocational Training, Second Chance Schools, Lifelong Learning Centers, etc., who want to upgrade their knowledge and gain additional degree. 


\section{Implementation Methodology}

\section{Blended Learning Model}

As mentioned above, the Center of Training and Lifelong Learning at the Aristotle University of Thessaloniki implements training programs either via face-to-face teaching or e-learning teaching methods. The implementation of the program we are examining in this study was based on the blended learning model.

Blended learning has various definitions in the literature. The first concrete definition of the term appears in 2006 with The Handbook of the Blended Learning (Bonk \& Graham, 2006). Graham defined "blended learning systems" as learning systems that "combine face-to-face instruction with computer mediated instruction." Other authors give wider definitions considering that blended learning means to personalize and individualize the teaching and learning activity, according to different learning needs of each learner (McSporran \& King, 2005). However, the most definitions agree that the goal is to combine face-to-face education and online education in an efficient way, which best fits to individuals (Yigit, Koyun, Yuksel \& Cankaya, 2014).

The term blended learning is based on constructivist theories about learning of Piaget, Dewey, Vygotsky, and Heinze, who theorized that participants have the opportunity to construct by themselves new knowledge and ideas that are based on their previous personal experience. The role of the trainer is to offer a great variety of exercises and learning experiences to learners in order to involve them and encourage them to use active methods, during which they should be able to independently achieve learning. Constructivist approach may be applied in the blended learning, as it offers participants various options in the architecture of knowledge: e-learning, sessions, adjustment to the trainees own learning style, workshops, simulations, written course aids, together with personal feedback from the trainer, who supervises and maximizes adult learners progress (Catalano, 2014).

The use of such a model of teaching and learning offers both advantages and challenges for participants. It may provide pedagogical benefits as increased learning effectiveness, satisfaction and efficiency. The University of Central Florida conducted a multi-year study examining the success rates of students attending face-to-face, blended learning, and online courses. The study found that the success rates for blended learning were higher than either fully face-to-face or fully online courses for both males and females. It has also been proven that blended learning increases access and flexibility in regards to time and space and makes participation possible for more people, for example, people living in rural areas far from institutions or employed people with limited free time. Additionally, using blended learning the operating cost is lower than face-to face teaching model. On the other hand, some challenges may become obstacles for adult participants, such as the need for computer skills and competence to use technology as a tool for communication and research (Graham, 2013; Porter, Graham, Spring \& Welch, 2014).

\section{Description of the Blended Learning Program Training of Lifelong Learning Adult Trainers}

The methodology used in this program was based on the principles of blended learning, as mentioned above, and on contemporary adult learning techniques, promoting active and experiential learning through action and learner-trainer interaction. 
By participating in the learning process, the adult trainee needs to acquire not only theoretical knowledge but also the practical knowledge of procedures, more specifically, how to do something. It is true that we learn something in relation to our present and past experience. The experience of a learner determines what he learns and the approach that he adopts to learning. Experiential learning theory defines learning as the process whereby knowledge is created through the transformation of experience. As adults have a rich foundation of experience and often these experiences are a rich resource for learning, greater emphasis can be placed on the techniques that tap their experience, such as group discussion, case studies, critical-incident process, simulation exercises, role playing, and skill practice exercises (Knowles, 1980; Pampouri \& Sipitanou, 2016).

The structure of the training program that we are examining included 10 modules of education and learning in a blended learning environment. In particular, the thematic modules combined eight to 16 synchronous tele-education sessions and one to three face-to-face meetings for guidance and feedback, while the educational process was supported throughout the program by using a synchronous-asynchronous platform (Moodle) of the Aristotle University of Thessaloniki.

The trainees participated in synchronous teleconferences, videoconferences, exercises, and case studies for each of the modules and were ensured continued access to educational material and bibliography. Also, they used a forum in order to interact with their instructors and each other, as well as for guidance, support, and problem solving.

At the end of the program, the trainees were divided into groups of 10-12 in order to present their micro-teaching that they had prepared during the program. Upon completion of the program and the award of the certificate, the trainees evaluated the program by completing an electronic questionnaire.

\section{Evaluation of Educational Programs}

It is well known that, in today's knowledge society, that the continuous monitoring and improving of the quality of educational services offered by universities and institutions is crucial as the quality of instruction impacts overall economic development (Pampouri, Tsipa, Mavropoulos, \& Tsipas, 2003). Educational evaluation can refer to the educational objectives, to the methods of teaching, to the curriculum, to the effectiveness of teaching, to the teaching staff, and also to a training program or even the educational system as a whole. More specifically, the evaluation of an educational program produces feedback to improve the learning process as well as the program (McGee \& Reis, 2012; Taylor \& Newton, 2012; Vergidis, 2001; Pampouri, 2014).

Research also outlines factors that make it difficult to evaluate a program. Due to the minimum physical contact time between trainees and trainers, informal communication is hampered and it is difficult to build a solid foundation of trust and communication. Also, there is no possibility to discuss the results of the evaluation and to clarify certain points. At the same time, trainees often find it difficult to express "sensitive" comments through forums or emails (Kälberer, Petendra, Böhmer, Schibelbein, \& Beck-Meuth, 2016).

Scriven proposed for first time in 1967 today's classical classification of types of evaluation based on their purpose, introducing formative and summative evaluation (Karalis, 1999). In the case of the 
training program we are considering, the evaluation type used was the summative evaluation with the use of a questionnaire. Summative evaluation means the assessment conducted in order to get conclusions about the value of a program and which is usually combined with the continuation or expansion of the program (Knox, 2002; McNamara, Joyce, \& O'Hara, 2010).

At the completion of the program, all trainees received by email a link to a questionnaire, which included closed-ended and open-ended questions. In particular, they were asked to fill in details of their profile, their educational level and the reasons for their participation. They were also asked to evaluate the quality of the program, the implementation methodology, the educational content, the micro-teaching process, and the whole organization of the program. We received 222 completed questionnaires.

\section{Results and Discussion}

\section{Trainees' Profile}

The overwhelming majority of the trainees attended the program for professional reasons. One of the main incentives for adults to participate in lifelong learning programs is for professional reasons. As shown in a survey of the National Statistical Service of Greece (NSSG) conducted in 2007 with a sample of 6,510 people aged 25-64, the largest percentage (78.4\%) said that they attended a program for professional reasons, $16.7 \%$ for personal reasons, and a small percentage (5\%) mentioned a combination of professional and personal reasons (Karalis, 2013). Karalis (2013, 2017) conducted a multi-year study in Greece, investigating the factors affecting adult participation in vocational training and general adult education programs. The study found that some of the main reasons for participation relate to job efficiency, maintaining a job position, or finding a better job.

\section{Overall Program Quality Evaluation}

Special attention was paid to the design of the program, which consisted of videoconferences, PowerPoint presentations, e-books, case studies, exercises, articles, and additional literature available for further study on the subject. With the support of the study guide and the timetable, the trainees were able to easily access all the educational material, as well as upload it to their computers for future use.

Since tuition could become a barrier to participation and prevent many prospective adult trainers from attending and completing the program (Koutouzis, 2013; Karalis, 2017), a low program cost was decided on. Indeed, $54 \%$ of the participants considered that the tuition fees were satisfactory, while $41 \%$ expressed they felt tuition was high and $5 \%$ felt they were very high, which shows that the tuition fees did not constitute a real barrier to participation.

\section{Program Methodology}

As discussed, combining face-to-face and distance learning resulted in synchronous tele-education sessions, asynchronous sessions through the e-learning platform of the university, as well as some face-to-face meetings that were scheduled in order to solve questions and provide better mentoring in the preparation of microteaching of trainees. The synchronous tele-education sessions were characterized as sufficient by an overwhelming majority of trainees (93\%). 
The asynchronous tele-education and videoconferences that were available for study in the e-learning platform, was reported as satisfactory by $91 \%$ of trainees. Through this platform, the trainees had access to educators' PowerPoint presentations, e-books, case studies, supplementary educational material, videoconferences adapted to the adult learning principles, and useful literature for further study.

The trainee's microteaching worked very positively, as that exercise enabled future adult trainers to translate into practice their theoretical knowledge acquired during the program (Pampouri \& Sipitanou, 2016), to apply various participatory teaching methods, as well as to demonstrate the multiple and complex individual skills and abilities they have acquired and managed to use in their microteaching. Numerous research studies, moreover, have highlighted the importance and effectiveness of microteaching, noting the significant improvement in the teaching skills of trainers. Microteaching may offer opportunities for self-knowledge to future trainers and may induce a critical examination of their teaching behavior. Consequently, it helps them to shape their didactic identity, to reflect on their teaching, and to achieve effective teaching practices (Kapsalis \& Vrettos, 2002; Giannakopoulou, 2008).

The learning modules content and presentations, both in face-to-face sessions as well as in synchronous and asynchronous sessions, were judged by $66 \%$ of the participants to be very clear and documented, $64 \%$ of them mentioned that they had direct relevance to each other, and $57 \%$ evaluated them as very well oriented to trainees' needs.

\section{Evaluation of the Program Organization}

Overall, the program was considered to be very well organized. In particular, $85 \%$ of the trainees evaluated the program's secretarial and administrative support as excellent. The infrastructure (the fundamental facilities of the program) was judged to be excellent by $48 \%$ and as very good by $46 \%$. Fourty five percent of trainees thought the venues where the face-to-face sessions took place were very satisfactory for meeting the needs of the program, while $40 \%$ of them found the facilities good enough. The main shortcomings reported were related to sound problems in some synchronous sessions, inappropriate classroom for face-to-face meetings (as there was no possibility of seating rearrangement), and difficulty in consolidating the learning content due to the large amount of educational material compared to program's time duration.

Several proposals were made for the improvement of the program. Some trainees suggested that it would help to provide more guidance and help in the preparation of microteaching, perhaps by dedicating another session. This proposal was taken into account during the evaluation and redesign of the program and was incorporated in a workshop in the context of the face-to-face session, which took place in the middle of the program. During the workshop, the trainees had the opportunity to design a microteaching with the guidance of the trainers. It was also proposed to allow more time to study during the week, so at the redesign of the program the sessions were made two per week instead of three. Finally, tests were added between the modules in order to facilitate better content consolidation and improve performance for the final examinations of the program. 


\section{Conclusion}

The evaluation of the program indicated that the training program Training of Lifelong Learning Adult Trainers at the Aristotle University of Thessaloniki was of high-level and value, well-organized, and with valuable educational material. The blended learning model worked efficiently and positively for trainees. Its flexibility gave participants the opportunity to attend the program even with their busy schedules. This success satisfied one of the main aims of the program, which was to enhance employability through participation in lifelong learning (Karalis, 2013; Karalis, 2017; McGee \& Reis, 2012; Taylor \& Newton, 2012).

The use of the blended learning model proved very effective (Graham, 2013; Porter, Graham, Spring, \& Welch, 2014). It would be useful to carry out a comparative study between blended learning programs implemented by Greek universities and similar programs in other countries which follow identical or different education models, in order to highlight good practices that could also be used in Greece. 


\section{References}

Bonk, C. J., \& Graham, C. R. (Eds.) (2006). The Handbook of Blended Learning: Global Perspectives, Local Designs. San Francisco: Pfeiffer.

Catalano, H. (2014). The opportunity of blended-learning training programs in adult education Ascertaining study. Procedia - Social and Behavioral Sciences, 142, 762-768. doi: 10.1016/j.sbspro.2014.07.612.

Giannakopoulou, E. (2008). Microteaching in training of adult trainers: from feedback to reflection. Adult Education, 14, 11-16. Retrieved from https://www.academia.edu/2237250

Graham, C. R. (2013). Emerging practice and research in blended learning. In M. J. Moore (Ed.), Handbook of distance education (3rd ed.; pp. 333-350). New York, NY: Routledge. Retrieved from http://www.academia.edu/2068375

Kälberer, N., Petendra, Br., Böhmer, C., Schibelbein, A., \& Beck-Meuth, E.M. (2016). Evaluation process and quality management in a blended-learning bachelor's programme. Procedia Social and Behavioral Sciences, 228, 131-137. doi: 10.1016/j.sbspro.2016.07.019

Kapsalis, A., \& Vrettos, I. (2002). Microteaching and exercising teaching skills. Athens: Atrapos.

Karalis, T. (1999). Typologies and evaluation models. In A. Kokkos (Ed.), Adult education: Planning, organization and program evaluation (pp. 128-142). Patra: Hellenic Open University.

Karalis, T. (2013). Motivation and barriers to the participation of adults in lifelong education. Athens: Labour Institute of Trade Union Confederation and the Small Enterprises Institute of General Confederation of Professionals, Craftsmen and Merchants of Greece (ISBN: 978960957134-0). Retrieved from https://www.researchgate.net/publication/246546970

Karalis, T. (2017). Shooting a moving target: The Sisyphus boulder of increasing participation in adult education during the period of economic crisis. Journal of Adult and Continuing Education, 23(1), 78-96. doi: 10.1177/1477971417691782

Knowles, M. S. (1980). The modern practice of adult education: From pedagogy to andragogy. Englewood Cliffs, NJ: Cambridge Adult Education.

Knox, B. A. (2002). Evaluation for continuing education - A comprehensive guide to success. San Francisco: Jossey- Bass.

Kokkos, A. (2007). The adult educators training program. Katartizein, 14, 4-5.

Kokkos, A. \& Karalis T. (2011). Planning and evaluation issues of the national adult educators education program. In A. Papastamatis, E. Valkanos, E. Panitsidou, \& G. Zarifis (Eds.), Lifelong learning \& adult educators. Thessaloniki: University of Macedonia Press.

Koutouzis, M. (Ed.). (2013). Leakage from adult lifelong learning structures. Research on an obscure problem. Athens: KANEP-GSEE. Retrieved from https://www.researchgate.net/publication/283727521 
McGee, P., \& Reis, A. (2012). Blended course design: A synthesis of best practices. Journal of Asynchronous Learning Networks, 16(4), 7-22. Retrieved from https://eric.ed.gov/?id=EJ982678

McNamara, G., Joyce, P., \& O’Hara, J. (2010). Evaluation of adult education and training programs. International Encyclopedia of Education (Elsevier), 548-554. doi: 10.1016/B978-0-08044894-7.01647-X.

McSporran, M., \& King, C. (2005). Blended is better: Choosing educational delivery method. In P. Kommers \& G. Richards (Eds.), Proceedings of ED-MEDIA 2005--World Conference on Educational Multimedia, Hypermedia \& Telecommunications (pp. 4932-4939). Montreal, Canada: Association for the Advancement of Computing in Education (AACE). Retrieved from https://www.learntechlib.org/p/21876/

Pampouri, A. (2014). Development and implementation of an internal evaluation model at a higher education institution. The International Journal of Adult, Community and Professional Learning, 2O(3), 53-61. doi: 10.18848/2328-6318/CGP/v20io3/48287.

Pampouri, A., Tsipa, M.L., Mavropoulos, A., \& Tsipas, D. (2003). Development and implementation of a pilot internal evaluation programme on post graduate programmes. In G. Papadourakis (Ed.)., Proceedings of the 3rd International Conference on New Horizons in Industry and Education (NIHE 2003; pp. 167-172).-Heraklion: Technological Educational Institute of Crete. ISBN 960-85316-7-5.

Pampouri, A., \& Sipitanou, A. (2016). Work-based learning as a means of professional development of graduates of higher education in their transition to the labor market: Research review. In S. Giosi \& I. Tsiafis (Eds.), Proceedings of the 6th National Conference on Standardization, Protypes and Quality (pp. 677-689). Thessaloniki: Union of Hellenic Scientists for Protypation and Standardization (ENEPROT). ISBN 978-960-9555-03-6.

Porter, W. W., Graham, C. R., Spring, K. A., \& Welch, K. R. (2014). Blended learning in higher education: Institutional adoption and implementation. Computers and Education, 75, 185195. doi: 10.1016/j.compedu.2014.02.011.

Taylor, J. A., \& Newton, D. (2012). Beyond blended learning: a case study of institutional change at an Australian regional university. The Internet and Higher Education, 18, 54-60. doi: 10.1016/j.iheduc.2012.10.003.

Vergidis, D. (2001). The contribution of evaluation to educational policy. In G. Bagakis (Ed.), Evaluation of educational programs and school. (pp. 40-60). Athens: Metaichmio.

Yigit, T., Koyun, A., Yuksel, A. S., \& Cankaya, I. A. (2014). Evaluation of blended learning approach in computer engineering education. Procedia - Social and Behavioral Sciences, 141, 807-812. doi: 10.1016/j.sbspro.2014.05.140. 
Training of Adult Trainers: Implementation and Evaluation of a Higher Education Program in Greece Mavropoulos, Sipitanou, and Pampouri

Athabasca

University

(c) 